\title{
THE NATIONAL FOOD CONTROL SYSTEM IN GUYANA: EVALUATION OF THE CURRENT REGULATORY FRAMEWORK FOR FOOD CONTROL SYSTEMS
}

\author{
Maya A. Phillips ${ }^{*}$, Neela Badrie ${ }^{2}$ and Marsha Singh ${ }^{3}$ \\ ${ }^{1,2,3}$ Faculty of Food and Agriculture, The University of the West Indies, Trinidad \\ ${ }^{1}$ Email: maya.phillips@my.uwi.edu; phillips_maya@rocketmail.com *(Corresponding author) \\ ${ }^{2}$ Email: neela.badrie@sta.uwi.edu; nbadrie@yahoo.com \\ ${ }^{3}$ Email: marsh.singh@sta.uwi.edu; marsha_ggg@hotmail.com
}

\begin{abstract}
The national food control system in Guyana is fragmented. It is a multiple agency system where multiple governmental agencies across various Ministries of Government are responsible for different aspects of food control. Overlaps in responsibilities arise from agencies sharing the responsibility for a particular industry or sharing food related legislation and/or regulations. Gaps in the food control system include the skills gap, the lack of a database to share information between agencies, slow surveillance system for foodborne diseases, largely paper based documentation system, poor harmonization of national standards with international standards, lack of adequate quarantine facilities, and the lack of a robust traceability system from farm to table. Outdated legislation and weak communication pathways are major weaknesses in the current regulatory framework for food control in Guyana. Guyana needs to address the overlaps, gaps, and weaknesses in the current national food control system. It is recommended in the short term that Guyana establishes formal channels of communication such as Memoranda of Understanding (MOU) between agencies responsible for food in Guyana, expand Guyana's human resource capacity by training personnel in various aspects of food control, and design and implement Public Service Announcements (PSAs) for food safety and food quality. In the medium term, it is recommended that Guyana establishes a Ministry of Food Production, develops accompanying Regulations for the new Food Safety Legislation (Act) following the passage of the Draft Food Safety Bill 2016 Bill no. 22 of 2016, designs a national policy for genetically modified (GM) foods, certifies public abattoirs, establishes quarantine facilities and regulations to govern operations, and develops a database with baseline data for heavy metals in the water supply. In the long term it is recommended that the country establishes a Food Safety Authority and improves laboratory infrastructure and capabilities.
\end{abstract}

Keywords: National Food Control Systems; Food Legislation and Regulations; Guyana.

https://doi.org/10.47412/CDOB4139

\section{Introduction}

A well-functioning national food control system increases a nation's food security and builds international credibility. One of the building blocks of a national food control system is food law and regulations [1]. The protection of public health and the prevention of unfair trade practices are the two principal concerns of modern food law [2]. Food law and regulations should be relevant and enforceable. The primary targets 
of food law are food businesses as it is their responsibility to ensure the safety of food and food products [3]. Food law has traditionally consisted of legal definitions of unsafe food, enforcement tools for removing unsafe food from commerce, and penalties for the responsible parties [1]. Food legislation should be specific to the realities of the country, provide for a centralization of authority, and have a biosafety approach $[4 ; 5]$.

Many times, countries are regulating their food industry using outdated legislation, and new regulatory agencies are established without a clear mandate in law [1]. This leads to situations where one legislation provides the legal basis for multiple agencies to operate. The result is a system of confusion with poor cooperation and communication between agencies. Outdated legislation has a direct impact on the standards for the food industry. Ideally food regulations and standards should be influenced by international agreements and standards such as Codex, and should promote the use of international best practices along the farm to table continuum.

Developing countries tend to have inadequate food control infrastructure [1]. This is due to limited resources, poorly equipped laboratories, the lack of skilled personnel or suitably trained analytical staff, and the absence of a fully risk-based approach to food control. In many developing countries the food control system is fragmented, and poorly regulated. This increases the risk of food being exposed to unhygienic practices and unsanitary environments, the contamination of food and food products by biological, chemical and physical hazards, food adulteration, and food fraud. These challenges arise because of poor food handling, food hygiene and agricultural practices, poor processing and storage practices, inadequate infrastructure, and the lack of a qualified, well-trained, well equipped, efficient and honest inspectorate.

The national food control system is responsible for the safety of food within the borders of a country [6]. Governments create a national food control system based on the hazards identified in foods [7]. Effective national food control systems are essential for public health and consumer confidence. Globally there is an effort by countries to update their food legislation and regulations. Past foodborne disease outbreaks have underscored the need for countries to have preventive rather than reactive food control systems. Some countries have resorted to modifying their national food control system from a previously fragmented multiple agency system to an integrated system or consolidating the responsibility for food control to a single agency system [8].

In Guyana, the national food control system is fragmented [9]. It is a multiple agency system where multiple institutions and agencies are responsible for different aspects of food control [8]. These institutions and agencies are housed under Ministries of Government and have their own independent administrative structure. Most have an inspectorate, an education and training arm, a communication or public relations section, and laws and regulations that govern operations.

The responsibility for food control in Guyana is shared mainly between the Ministry of Public Health and the Ministry of Agriculture. Agencies housed under other Ministries are also involved in food control. With this fragmented system and the country's bureaucracy there exists an environment where regulatory organisations for food compete rather than cooperate. The objectives of this paper were to determine the overlaps in the responsibilities of the regulatory agencies involved with food control in Guyana, the gaps in the food control system, and the weaknesses in the current framework. 


\section{Methodology}

\subsection{Scope of Research}

The food laws and regulations of Guyana were evaluated using a qualitative study design to determine gaps, overlaps, and weaknesses in the current regulatory framework. Data collected from legislative, organisational and archival policy documents were supplemented with key stakeholder interviews.

\subsection{Data}

Data was collected from primary and secondary sources. Primary data sources included interviews with key stakeholders. Given that the food control system in Guyana is fragmented, key stakeholders from various public sector departments and government ministries were interviewed.

Sixteen (16) interviews were conducted with stakeholders from five (5) different Ministries of Government and one (1) stakeholder from an international organisation responsible for food control in Guyana. An extensive list of interview guide questions was used to gather relevant information on the national food safety laws and regulations in Guyana while concentrating on the following: (i) the roles and mandates of the regulatory organisations involved, (ii) the existing food legislation, food regulations, and standards, and (iv) the level of cooperation, collaboration, and coordination between the regulatory organisations involved with food control in Guyana.

Secondary data sources included Acts of Parliament and archival documents. Health and agricultural policy documents, organisational documents, and legislative documents relevant to food control were reviewed. Specific focus was placed on the mandates, and legislative framework of the regulatory organisations (institutions, agencies, departments, government ministries, city councils) involved with food control in Guyana.

\subsection{Analysis of Data}

Handwritten notes were made of key points and at different stages of the interviews stakeholders were asked to confirm whether the points written by the author were accurate representations. The points were further investigated using archival documents and the information documented was extracted and presented according to themes: overlaps in responsibilities, gaps in the food control system, and weaknesses in the current framework.

\section{Results and Discussion}

The Government of the Cooperative Republic of Guyana remains the dominant player in policy setting and the enactment of laws that provide the legal basis for institutions and agencies to operate. The Government is principally responsible for the national food control system in Guyana, a responsibility which is shared mainly between the Ministry of Public Health and the Ministry of Agriculture. Institutions and agencies housed under the Ministries of Business, Communities, Finance, and the Ministry of the Presidency also have lesser, still important roles in food control. Table 1 shows the main food related responsibilities of each regulatory agency involved with food control in Guyana. 
Table 1: The ministries, institutions and agencies involved with food control in Guyana

\begin{tabular}{|c|c|c|}
\hline Ministry & Institution/Agency & $\begin{array}{c}\text { Main Responsibility (food } \\
\text { related) }\end{array}$ \\
\hline \multirow[t]{2}{*}{$\begin{array}{l}\text { Ministry of Public } \\
\text { Health }\end{array}$} & $\begin{array}{l}\text { Government Analyst-Food and Drug } \\
\text { Department (GA-FDD) }\end{array}$ & $\begin{array}{l}\text { Laboratory (Food Microbiology, } \\
\text { Food Chemistry, Water } \\
\text { Chemistry) }\end{array}$ \\
\hline & Veterinary Public Health Unit (VPHU) & Seafood and Meat \\
\hline \multirow[t]{10}{*}{$\begin{array}{l}\text { Ministry of } \\
\text { Agriculture }\end{array}$} & Fisheries Department & $\begin{array}{l}\text { Marine and Inland Fishery, } \\
\text { Aquaculture }\end{array}$ \\
\hline & $\begin{array}{ll}\text { Guyana Livestock } & \text { Development } \\
\text { Authority (GLDA) } & \\
\end{array}$ & $\begin{array}{l}\text { Animal Production, Animal } \\
\text { Health, Animal Husbandry }\end{array}$ \\
\hline & Guyana Marketing Corporation (GMC) & Agro-Processing and Packaging \\
\hline & Guyana Rice Development Board (GRDB) & Rice, Seed Production \\
\hline & Guyana Sugar Corporation (GuySuCo) & Sugar, Molasses \\
\hline & $\begin{array}{l}\text { Hydrometeorological Service (Hydromet } \\
\text { Department) }\end{array}$ & $\begin{array}{l}\text { Climatology, } \quad \text { Hydrology, } \\
\text { Meteorology, Oceanography }\end{array}$ \\
\hline & $\begin{array}{l}\text { Mahaica/Mahaicony/Abary-Agricultural } \\
\text { Development Authority (MMA/ADA) }\end{array}$ & $\begin{array}{l}\text { Water Control, Drainage and } \\
\text { Irrigation Services }\end{array}$ \\
\hline & $\begin{array}{l}\text { National Agricultural Research \& } \\
\text { Extension Institute (NAREI) }\end{array}$ & $\begin{array}{ll}\text { Crop Production, } & \text { Crop } \\
\text { Diversification } & \\
\end{array}$ \\
\hline & $\begin{array}{l}\text { National Drainage and Irrigation Authority } \\
\text { (NDIA) }\end{array}$ & $\begin{array}{l}\text { Water Distribution, Drainage and } \\
\text { Irrigation Services }\end{array}$ \\
\hline & $\begin{array}{l}\text { Pesticides and Toxic Chemicals Control } \\
\text { Board (PTCCB) }\end{array}$ & $\begin{array}{lcr}\text { Pesticide } & \text { Products, } & \text { Pesticide } \\
\text { Residue, } & \text { Maximum } & \text { Residual } \\
\text { Limits } & & \\
\end{array}$ \\
\hline Ministry of Business & $\begin{array}{l}\text { Guyana National Bureau of Standards } \\
\text { (GNBS) }\end{array}$ & $\begin{array}{lrr}\text { Food } & \text { Standards, } & \text { Agriculture } \\
\text { Standards, Training } & \\
\end{array}$ \\
\hline $\begin{array}{l}\text { Ministry } \\
\text { Communities }\end{array}$ & $\begin{array}{l}\text { Mayor and City Council (M\&CC) of } \\
\text { Georgetown Meat and Hygiene Food } \\
\text { Department and Municipal Abattoir }\end{array}$ & $\begin{array}{l}\text { Municipal Markets, Meat Stalls, } \\
\text { Legal slaughter of food animals }\end{array}$ \\
\hline Ministry of Finance & Guyana Revenue Authority (GRA) & Customs: Import and Export \\
\hline $\begin{array}{l}\text { Ministry of the } \\
\text { Presidency }\end{array}$ & $\begin{array}{l}\text { Environmental Protection Agency (EPA), } \\
\text { Department of Environment }\end{array}$ & $\begin{array}{ll}\text { Environment } & \text { Management, } \\
\text { Pollution Control } & \\
\end{array}$ \\
\hline
\end{tabular}

\subsection{Overlaps in Responsibilities}

Overlaps exist in the sharing of regulatory responsibility, and the sharing of legislation between agencies that lack their own legislation to govern their operation.

\subsubsection{Laboratory Infrastructure}

In cases where the institution lacks the laboratory infrastructure, the national laboratory formally known as the Government Analyst-Food and Drug Department (GA-FDD) of the Ministry of Public Health conducts testing. This overlap persists because of budgetary constraints. The lack of financial resources to improve laboratory capabilities and the level of human resources has caused some agencies to be unable to fulfil their mandate of having a well-functioning inspectorate. 


\subsubsection{The Fish Industry}

The inspectorate responsibility for the fish industry in Guyana is shared by two governmental agencies: the Fisheries Department of the Ministry of Agriculture; and the Veterinary Public Health Unit (VPHU) of the Ministry of Public Health. The Fisheries Act of 2002 [10] is the legal basis for the Fisheries Department of the Ministry of Agriculture to operate. However, the accompanying Fisheries Product Regulations of 2003 [11] guides the operations of the Veterinary Public Health Unit (VPHU) of the Ministry of Public Health. This makes the VPHU the competent authority for those Regulations. The Fisheries Department oversees fishing, the activities of fishing vessels and fish farming, licenses and inspects fish processing plants, and issues export licences for fish and fish products. The VPHU also has a responsibility for inspecting and certifying processing establishments as well as certifying all fishery products, and inspecting seafood at international ports.

Once the fish is alive it is the responsibility of the Fisheries Department. Fish would become the responsibility of the VPHU during the processing and packaging step at fish processing plants. This has led to confusion, and reduced the credibility of the fish inspection system in Guyana. In early 2018, Guyana lost a valuable market for all Siluriformes fish (catfish). This was due to a ban imposed by the United States Department of Agriculture (USDA). In an effort to protect their consumers, the United States banned the import of Sciades parkeri (Gilbacker sea catfish) and other fish species including Hoplosterum sp. locally known as 'Hassa', and Sciades proops locally known as 'Cuirass' from Guyana.

The US fish ban was primarily due to the poor inspection system for fish in Guyana. Although the Food Safety and Inspection Service (FSIS) of the United States in 2015, three years prior to the fish ban, had notified the Fisheries Department of the Ministry of Agriculture of the need to improve the fish inspection system in Guyana, it was ultimately the responsibility of the Veterinary Public Health Unit (VPHU) of the Ministry of Public Health to satisfy the US requirements.

\subsubsection{The Meat Industry}

The VPHU lacks its own legislation to govern its operation. This presents another overlap since legislation is shared between agencies. The Government Analyst-Food and Drug Department (GA- FDD) falls under the purview of the Ministry of Public Health. Originally established to perform analysis for the sugar industry in the late 19th century, the department now focuses on food, drugs, cosmetics, and therapeutic devices. The VPHU and the GA-FDD share responsibility for Chapter 34:03 Food and Drug Act 1971 [12]. This Act is primarily intended to provide the legal basis for the GA-FDD to operate. However, Section 20 of Chapter 34:03 Food and Drug Act along with the Public Health Ordinance Chapter 145 provides the legal basis for the VPHU to operate within the meat industry in Guyana [12;13].

The Guyana Livestock Development Authority (GLDA) of the Ministry of Agriculture is the competent authority for animal health, production, inter alia, in Guyana. GLDA conducts ante-mortem inspection of livestock. Post-mortem inspection is conducted by the VPHU. The VPHU also conducts inspection of meat and meat products at international ports, inspection and certification of abattoirs used for export purposes, and monitoring of farms.

\subsection{Gaps in the Food Control System}

Budgetary constraints have weakened the national food control system in Guyana and perpetuated a skills gap. Limited financial resources have prevented agencies from increasing staff. Instead staff are outsourced from sister agencies. In the current multiple agency system, this is a good approach to managing resources. However, it shows the limits of the inspectorate and enforcement capabilities of individual agencies.

There is no database for the sharing of information between agencies involved in food control in Guyana. The current surveillance system for foodborne diseases results in slow outbreak detection, and poor estimation of the foodborne disease burden in Guyana. Another gap exists in documentation. 
Documentation systems continue to be largely paper based. National standards are not harmonized with international standards such as Codex Alimentarius and the World Organisation for Animal Health (OIE) standards. Guyana lacks adequate quarantine facilities, and there is no legal document stipulating quarantine requirements.

The country also lacks robust traceability systems from farm to table. There is no system to track animals and animal products, and crops especially fruits and vegetables back to the farm of origin. Recall systems for manufactured food products are non-existent.

\subsection{Weaknesses in the Current Framework and Recommendations for Improvement}

More emphasis must be placed on locally produced products sold on the local market. Advances in technology and the use of social media have increased the speed at which information travels globally. Consumers in Guyana are now putting more pressure on regulators to implement better food safety and food quality requirements for local manufacturers. Labelling, packaging, traceability and recall requirements have now taken the front burner.

The Guyana National Bureau of Standards (GNBS) has been conducting public consultations on the specifications for the labelling of pre-packaged foods in keeping with the Caribbean Community (CARICOM) standard. There has also been a coordinated effort between the public and private sector to train more local food producers and manufacturers in international best practices such as Good Agricultural Practices (GAPs), Good Manufacturing Practices (GMPs), and Hazard Analysis and Critical Control Point (HACCP). Regulatory agencies are also investing in training for their inspectors. Most of the training is done locally by the Guyana National Bureau of Standards (GNBS) of the Ministry of Business, which is the Codex Contact Point for Guyana.

\subsubsection{Outdated Legislation}

Outdated legislation presents another weakness for the national food control system in Guyana. Efforts have been made to upgrade laws to reflect current international best practices and standards. Few food related laws remain unchanged. A popular misconception is that the Government Analyst-Food and Drug Department (GA-FDD) of the Ministry of Public Health is the agency responsible for all aspects of food in Guyana. Scrutiny of Chapter 34:03 Food and Drug Act of 1971 [12] and its corresponding Regulations of 1977 [14], shows that only a small section actually focus on food and food safety issues. Much more emphasis is placed on pharmaceutical drugs, cosmetics, and therapeutic devices. This Law since its enactment in 1971, has never been amended [12].

\subsubsection{Communication Pathways}

Another weakness in the current food control system in Guyana is the pathways for communication between agencies. As mandated by law, boards and committees exist across Ministries and are responsible for different aspects of food control. These include the Central Board of Health, Fisheries Advisory Committee, and the National Conformity Assessment Committee. However, the communication pathways between the agencies involved in Guyana's fragmented food control system are mostly informal and personal. These pathways generally cease to exist as persons leave agencies. The result is a lull in communication before new pathways can be developed.

Few agencies have formal memoranda of understanding (MOU) between them. In the short term, it is recommended that more formal channels of communication, for example through Memoranda of Understanding (MOU), be established between agencies to improve the level of cooperation. Public Service Announcements (PSAs) for food safety and food quality should also be designed and implemented and there should be a database to allow the sharing of information between agencies to avoid overlaps. 


\subsubsection{Personnel}

In the short term, Guyana needs to expand the human resource capacity by training personnel in various aspects of food control. As Guyana transitions to the single agency system there needs to be a clear structure of roles and responsibilities. Staff should be working according to their job description. Food safety specialists can be employed and training should be provided to current staff to make the transition smoother. A project should be undertaken to determine the specific skills needed for the Food Authority. This will also enable Guyana to garner much needed financial support from international organisations and partnering countries to facilitate training.

\subsubsection{The Food Authority}

Guyana lacks a Food Authority. This presents a major weakness in the current framework. The Draft Food Safety Bill 2016 Bill no. 22 of 2016 [15], makes provision for the establishment of a Food Authority. This Authority would be responsible for implementing and enforcing the provisions of this Act, implementing any technical standards within the contemplation of this Act, and providing persons engaged in food business with general guidance on equipment sanitation, operational sanitation, production or processing practises for any food or agricultural input and the use of specified pesticides and other agricultural inputs [15].

The main aim of Guyana having the Food Safety Authority is to facilitate audits, ensure international compliance, enforce plant protection and animal health certification systems and food standards, and to facilitate training and other functions. Most importantly the country will have an overarching institution responsible for all aspects of food safety. The establishment of a Food Authority would mean Guyana has successfully transitioned from the multiple agency system of food control to the single agency system.

In the medium term, it is recommended that Guyana establishes a Ministry of Food Production, develops accompanying Regulations for the new Food Safety Legislation (Act) following the passage of the Draft Food Safety Bill 2016 Bill no. 22 of 2016 [15], designs a national policy for genetically modified (GM) foods, certifies public abattoirs, establishes quarantine facilities and regulations to govern operations, and develops a database with baseline data for heavy metals in the water supply.

In the long term it is recommended that the country establishes a Food Safety Authority, and improves laboratory infrastructure and capabilities. This will ultimately build credibility in Guyana's national food control system.

\section{References}

[1] FAO and WHO (Food and Agriculture Organization of the United Nations and World Health Organization). 2003. Assuring Food Safety and Quality: Guidelines for Strengthening National Food Control Systems. FAO Food and Nutrition Paper 76.

[2] Scott, Colin. 1990. "Continuity and Change in British Food Law." The Modern Law Review 53 (6): 785801. Accessed October 1, 2018. https://www.jstor.org/stable/1096391?seq=1\#page_scan_tab_contents

[3] Meulen, Bernd van der. 2010. "The Function of Food Law: On the objectives of Food Law, Legitimate Factors and Interests into Account." European Food and Feed Law Review 5 (2): 83-90. Accessed October 2, 2018. https://www.jstor.org/stable/24325791?seq=1\#page_scan_tab_contents

[4] FAO (Food and Agriculture Organization of the United Nations). 2005. Perspectives and Guidelines on Food Legislation, with a New Model Food Law. FAO Legislative Study 87.

[5] Kelly, Jeanelle Teres La Reina. 2018. "Evaluating the National Food Control System in St. Kitts and Nevis: A Closer Look at the Food Safety Laws." Master's thesis. The University of the West Indies, St. Augustine, Trinidad and Tobago.

[6] CAC (Codex Alimentarius Commission). 2013. Principles and Guidelines for National Food Control Systems. Rome, Italy. 
[7] Neeliah, Shalini and Daya Goburdhun. 2007. "National Food Control Systems: A Review." Food Reviews International $23 \quad$ (1): 35-51. Accessed August 20, 2018. https://doi.org/10.1080/87559120600998148

[8] Al-Kandari, Dina and David J. Jukes. 2012. "The Food Control System in Saudi Arabia-Centralizing Food Control Activities." Food Control 28 (1): 33-46. Accessed August 20, 2018. doi:10.1016/j.foodcont.2012.03.030

[9] Collins, Marilyn. 2015. "Strengthening Food Safety Systems in Guyana." Accessed June 20, 2018. https://www.stabroeknews.com/2015/business/07/10/strengthening-food-safety-systems-in-guyana/ [10] Guyana. House of Assembly. 2002. Fisheries Act, 2002.

[11] Guyana. House of Assembly. 2003. Fisheries Product Regulations, 2003.

[12] Guyana. House of Assembly. 1971. Chapter 34:03 Food and Drugs Act, 1971.

[13] Guyana. House of Assembly. 1970. Public Health Ordinance, 1970.

[14] Guyana. House of Assembly. 1977. Food and Drugs Regulations, 1977.

[15] Guyana. House of Assembly. 2016. Draft Food Safety Bill 2016 Bill no.22 of 2016, 2016. 